Z. klin. Chem. u. klin. Biochem.

8. Jg., S. 293-298, Mai 1970

\title{
Die immunologische Identifizierung und Lokalisierung der Proteinfraktionen nach disk-elektrophoretischer Trennung auf Polyacrylamidgel ${ }^{1}$ )
}

\author{
Von M. KRIEG ${ }^{2}$ ) und H. WeICKER \\ Aus der S. J. Thannbauser-Abteilung für Stoffivechseluntersucbungen (Vorstand: Prof. Dr. H. Weicker) \\ der Mediqinischen Universitäts-Poliklinik Heidelberg
}

(Eingegangen am 29. Januar 1970)

\begin{abstract}
Die immunologische Identifizierung des Disk-Elektrophorese-Spektrums wurde mit monovalentem Antiserum direkt auf dem Polyacrylamidgel nach elektrophoretischer Trennung von normalem Humanserum durchgeführt.

Folgende Proteine können durch Präzipitation im Gel nachgewiesen werden: $\alpha_{1}$-saures Glykoprotein, Präalbumin, Albumin, $\alpha_{1}-$ Antitrypsin, $\alpha_{1}$-Lipoprotein, Coeruloplasmin, Hämopexin. Transferrin, $\beta_{1}$-C/A-Globulin, Haptoglobin, $\alpha_{2}$-Makroglobulin, $\beta$-Lipoprotein, $\operatorname{Ig} A$ und IgG.

$\alpha_{1}$-Lipoprotein, Hämopexin, $\alpha_{1}$-Antitrypsin, IgG, IgA sowvie das $\alpha_{1}$-saurc Glykoprotein repräsentieren keine mit Amidoschwarz anfärbbaren Banden, da sich z. T. mehrere Proteinfraktionen überlagern.
\end{abstract}

\section{The immunological identification and localisation of protein fractions, following disc-electroplsoretic scparation on polyacrylamide gel}

1. The pattern of separation of normal human serum after disc electrophoresis was identified immunologically with monovalent antiserum directly on the polyacrylamide gel.

2. The following method was used:

a) Identification by diffusion of monovalent into the gel column with the formation of the immunoprecipitate after a few hours.

b) Electrophoretic washing of the gel column for 24-30 hr. to remove non-precipitated antigen and antiserum.

c) Staining the immunoprecipitate with amido black $10 \mathrm{~B}$.

d) Correlation of the precipitation bands with those of serum separated under the same conditions and stained with amido black.

3. The following classes of proteins can be shown in the gel column by precipitation: $\alpha_{1}$-acidic glycoprotein, pre-albumin, albumin, $\alpha_{1}$ antitrypsin, $\alpha_{1}$-lipoprotein, caeruloplasmin, haemopexin, transferrin, $\beta_{1}$-C/A-globulin, haptoglobulin, $\alpha_{2}$-macroglobulin, $\beta$-lipoprotein, IgA and IgG.

4. The following results were obtained from the comparison with the separation pattern in disc electrophoresis:

a) $\alpha_{1}$-lipoprotein, haemopexin, $\alpha_{1}$-antitrypsin, $\operatorname{IgG}, \operatorname{IgA}$, and $\alpha_{1}$-acidic glycoprotein do not represent bands detectable with amido black, since there is overlapping of protein bands.

b) In fresh serum, $\beta_{1}-\mathrm{C} / \mathrm{A}$-globulin consists of two fractions and in older serum it becomes three fractions.

c) Five $\mathrm{Hp}$ fractions of the $2-2$ type were detected immunologically between $\alpha_{1}$-macroglobulin and $\beta$-lipoprotein.

d) $\beta$-lipoprotein migrates into $5 \%$ gel, while $\operatorname{IgM}$ remains at the starting point.

Die von Ornstein (1) und Davis (2) entwickelte DiskElektrophorese-Technik an Polyacrylamidgel dürfte für die Proteintrennung eines der leistungsfähigsten Zonenelektrophorese-Verfahren darstellen. Ihre diagnostische Verwendung in der Serumauftrennung wird jedoch durch die Schwierigkeit der Interpretation der zahlreichen Proteinfraktionen eingeschränkt. $\mathrm{Da}$ die einzelnen Banden schon bei Normalserum in ihrer Lokalisation sehr variabel sind, und verschiedene Proteinfraktionen durch Überlagerung bei der. Amidoschwarzfärbung nicht zur Darstellung kommen, kann ihre Identifizierung nur immunologisch vorgenommen werden. Es war deshalb das Ziel dieser Untersuchungsreihe, die einzelnen Serumproteinfraktionen des Disk-Elektrophorese-Spektrums durch eine technisch einfache Immunpräzipitationsmethode direkt auf dem Polyacrylamidgel zu identifizieren.

1) Mit Unterstützung der Deutschen Forschungsgemeinschaft.

2) Diese Arbeit enthält wesentliche Teile der Dissertation von M. KRIEG.

\section{Material und Methode}

Normales Humanserum wird mit dem Disk-Elektrophoreseapparat der Firma Shandon in 5proz. $6-7 \mathrm{~cm}$ langem Polyacrylamidgel-Zylinder getrennt. Die Zusammensetzung der Stammlösung für das Gelsystem erfolgt nach Davis (2). Das Serum wird mit $1 \mathrm{M}$ Saccharoselösung auf $1: 10$ verdünnt und in einer Menge von $40 \mu l$ entsprechend 240-320 $\mu$ g Protein auf das Sammelgel aufgetragen. Die Anfangsstromstärke beträgt $2 \mathrm{~mA}$, bei Erreichung der Sammelgcl/Trenngelgrenze erhöhen wir auf $3 \mathrm{~mA} / \mathrm{Gel} .2 \mathrm{~m} l$ einer 0,001 proz. Bromphenolblaulösung markiert während der etwa 90 Min. dauernden Elektrophorese die Proteinfront.

Anschließend werden die Gele in kleine mit monovalentem Antiserum gefüllte Reagenzgläser (lichtc Weite: etwa $7 \mathrm{~mm}$, Länge: $8 \mathrm{~cm}$, NS 12,5 Schliffstopfen) gebracht, die in einem von uns konstruierten Rotationsgerät um ihre Längsachse mit $50 \mathrm{U}$./Min. rotieren. Die Rotationsdauer und Diffusionszeit betragen je nach Fragestellung 2-3 oder max. rund $24 \mathrm{Stdn}$. Die $2 \mathrm{ml}$ frisch zubereitete Reagenzglasfüllung bestehen im allgemeinen aus $1 \mathrm{ml}$ Antiserum und $1 \mathrm{~m} /$ physiol. NaCl-Lösung. Sie kann bis zu fünfmal wiederverwandt wcrden. Liegt ein erheblicher Antigenüberschuß vor (wie z. B. bcim Albumin), muß das Mischungsverhältnis und die Gesamtmenge des Antiscrums variicrt verden. Nach erfolgter Immundiffusion in das Trenngel lassen sich die 
wcißen Präzipitate mittels einer starken, diffusen Lichtquelle (Projektionslampe mit vorgesetztcm Milchglasspalt) deutlich sichtbar machen und photographieren.

Eine Anfärbung der Immunptäzipitate mit Amidoschwarz $10 \mathrm{~B}$ gelingt nach vorheriger elektrophoretischer Auswaschung der Gele von nichtpräzipitierten Antigen- und Antiserumanteilen. Wir benutzen hierfür einen von der Firma Desaga für die Entfärbung von Gelzylindern hergestellten Apparat. Die Elektrophoresekammer wird mit einem auf $1: 1000$ verdünnten Puffer folgender Zusammensetzung gefüllt: $2,5 \mathrm{~g}$ Tris $+1,0 \mathrm{~g}$ Glycin ad $100 \mathrm{ml}$ dest. Wasser $\mathrm{pH} 9,15 ; 1: 1000$ Verdünnung: $\mathrm{pH} \mathrm{8,8.}$ Mit diesem Puffer erhalten wir bei $9 \mathrm{~mA}$ konstant eingestellter Stromstärke eine Spannung von 220-260 V. Ein in der ersten Phase der elektrophoretischen Auswaschung erfolgender Spannungsabfall auf $50 \mathrm{~V}$ und darunter wird durch mehrmaliges Wechseln des Puffers ausgeglichen. Drei Gele sind gleichzeitig in der Kammer auf einem Netz horizontal fixiert. Die Auswaschung der nicht präzipitierten Proteine erfolgt vertikal und ist spätestens nach 30 Stdn. beendet.

Die anschließende Färbung mit Amidoschwarz $10 \mathrm{~B}$ dauert $30 \mathrm{Min}$. Die Entfärbung gelingt innerhalb von $12-16 \mathrm{Stdn}$. in einem 7proz. Essigsäurebad. Eine schnellere Entfärbung kann elektrophoretisch im Disk-Elektrophoreseapparat durchgeführt werden. Eine Beschreibung findet sich bei MAURER (3).

\section{Ergebnisse}

Folgende Befunde lassen sich nach Disk-Elektrophorese und Diffusion von monovalenten Antiseren erheben: Präalbumin wandert als diskrete Bande auch bei Untersuchungen desselben Humanserums mit unterschiedlich schneller Geschwindigkeit. In der Regel liegt es vor dem Albumin, gibt eine scharfe Präzipitation mit AntiPräalbuminserum und erlaubt eine exakte Zuordnung zum Disk-Elektropherogramm. In einzelnen Trennungen löst sich jedoch das Präalbumin trotz gleicher technischer Voraussetzungen nicht von der Albuminfraktion und kann dann nur durch monovalente Immunpräzipitation nachgewiesen werden (s. Abb. 1).

$\alpha_{1}$-saures Glykoprotein als kohlenhydratreichstes, neuraminsäurehaltiges Serum-Glykoprotein wandert schneller als Präalbumin und wird bei der im Serum vorliegenden Konzentration nicht mit wäßr., essigsaurem Amidoschwarz angefärbt. Der Nachweis im Trenngel gelingt

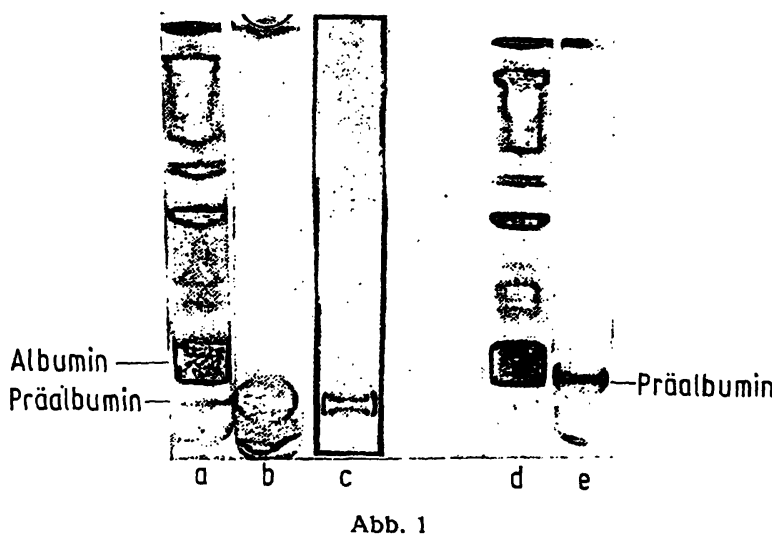

Identifizierung von Präalbumin. a = Disk-Elektrophorese von Humanserum mit isolierter Präalbuminbande. $\mathrm{b}=$ Angefärbtes Immunpräzipitat im Gelsaulchen nach Diffusion von Anti-Präalbuminserum gegen Humanserum. $\mathbf{c}=$ Ungefärbtes Immunpräzipitat im Gelsäulchen nach Diffusion von Anti-Präalbuminserum gegen Humanserum. $\mathrm{d}=$ Disk-Elektrophorese vom selben Humanserum wie in a ohne sichtbare Präalbuminbande. $e=$ Angefärbtes Immunpräzipitat im Gelsäulchen nach Diffusion von Anti-Präalbuminserum gegen Humanserum. Erst durch die Immunpräzipitation kann in dieser Trennung das Präalbumin nachgewiesen werden

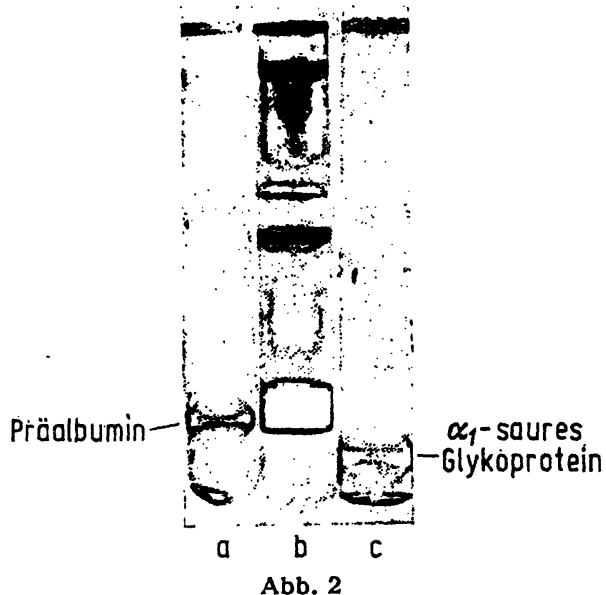

Identifizierung von $\alpha_{1}$-saurem Glykoprotein. $\mathrm{a}=$ Disk-Elektrophorese von Humanserum. $\mathbf{b}=$ Angefärb tes Immunpräzipitat im Gelsäulchen nach Diffusion von Anti- $\alpha_{1}-$ saurem Glycoproteinserum gegen Humanserum. $\mathrm{c}=$ Ungefärbtes Immunpräzipitat im Gelsäulchen nach Diffusion von Anti- $\alpha_{1}$-saurem Glykoproteinserum gegen Humanserum. Eine Zuordnung $\mathrm{zu}$ einer Bande der $\mathrm{Abb}$. $\mathrm{a}$ ist nicht möglich

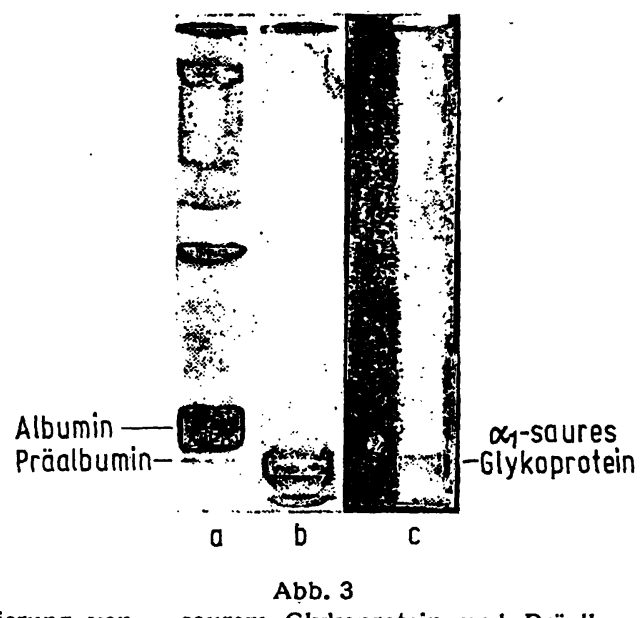

Identifizierung von $\alpha_{2}$-saurem Glykoprotein und Präalbumin. $a=$ Angefärbtes Immunpräzipitat im Gelsäulchen nach Diffusion von Anti-Präalbuminserum gegen Humanserum. $b=$ Disk-Elektrophorese von Humanserum ohne sichtbare Präalbuminbande. $c=$ Angefäres Immunpräzipitat im Gelsäulchen nach Diffusion von Anti- $\alpha_{1}-5 a u r e m$ Glykoprotein gegen Humanserum. Die Abb. zeigt deutlich, daB das $\alpha_{1}$-saure Glykoprotein schneller als das Präalbumin wandert, daß in keinem Fall im Disk-Elektropherogramm darstellen läßt

nur durch die monovalente Immunpräzipitation, die sich gut mit Amidoschwarz darstellen läßt (s. Abb. 2 und 3).

Das $\alpha_{1}$-Antitrypsin wandert mit gleicher Geschwindigkeit wie die Albuminfraktion und stellt deshalb keine eigene Bande im Disk-Elektropherogramm dar. Erst durch die Immunpräzipitation wird seine Lokalisation in der Albuminbande erkennbar.

Auch das $\alpha_{1}$-Lipoprotein ist im Elektropherogramm nicht sichtbar. Die ungefärbte, breite Immunpräzipitation mit monovalentem Anti- $\alpha_{1}$-Lipoproteinserum zeigt jedoch deutlich seine Lokalisation, die vom Albuminbereich bis zur Doppelbande des Coeruloplasmins reicht (s. Abb. 4).

Das Immunpräzipitat des Coeruloplasmins erlaubt eine Zuordnung $\mathrm{zu}$ den beiden nächstliegenden Banden anodisch vom Transferrin.

Das Transferrin selbst zeigt mit monovalentem Antiserum eine scharf begrenzte Präzipitationslinie, die sich eindeutig der mit Amidoschwarz angefärbten Bande zuordnen läßt. 


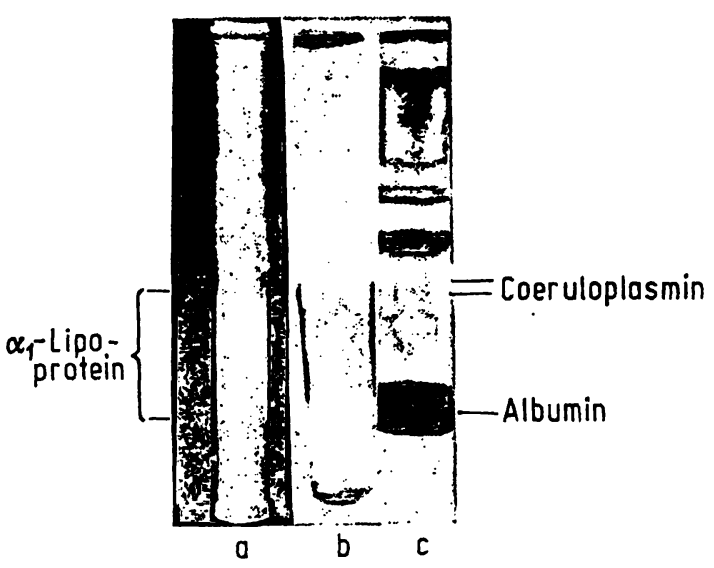

Abb. 4

Identifizierung von $\alpha_{1}$-Lipoprotein. $a=$ Ungefärbtes Immunpräzipitat im Gelsäulchen nach Diffusion von Anti- $\alpha_{1}$-Lipoproteinserum gegen Humanserum. $b=$ Angefärbtes Immunprăzipitat im Gelsäulchen nach Diffusion von Anti- $\alpha$ - -Lipoproteinserum gegen Humanserum. $c=$ Disk-Elektrophorese von Humanserum

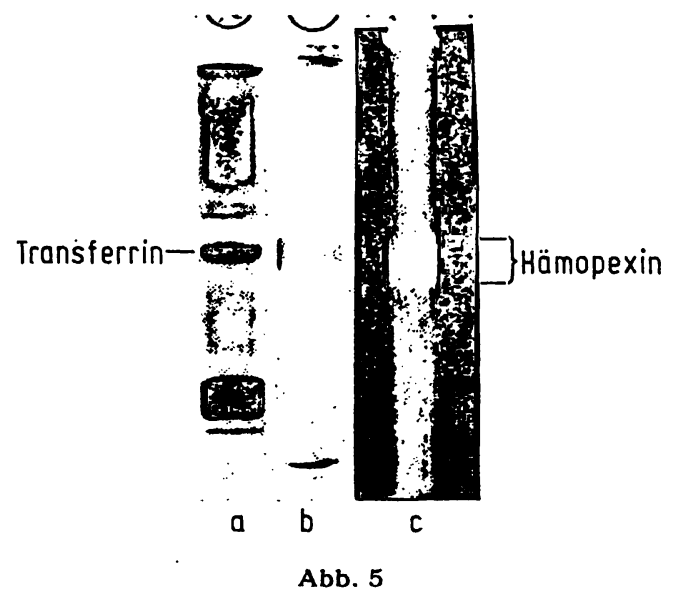

Identifizierung von Hämopexin. $\mathrm{a}=$ Disk-Elektrophorese von Humanserum. $b=$ Angefärbtes Immunpräzipitat im Gelsäulchen nach Diffusion von Anti-Hämopexinserum gegen Humanserum. $c=$ Ungefärbtes Immunpräzipitat im Gelsäulchen nach Diffusion von Anti-Hämopexinserum gegen Humanserum

Im Disk-Elektropherogramm ist das Hämopexin dagegen nicht eindeutig dargestellt. Das diffuse Immunpräzipitat beginnt vor dem kathodischen Rand des Transferrins und erreicht anodisch fast das Coeruloplasmin. Statt der sonst üblichen $1: 1$ Verdünnung benutzen wir beim Hämopexin eine $1: 4$ Verdünnung (d. h. 0,5 ml AntiHämopexinserum $+1,5 \mathrm{ml}$ physiol. $\mathrm{NaCl}$-Lösung) mit einer weit besseren Ausbildung des Immunpräzipitates (s. Abb. 5).

Mit der hier vorgeschlagenen Technik konnten wir erstmalig das $\beta_{1}-C$-Globulin und sein Transformationsprodukt disk-elektrophoretisch identifizieren. Im frischen Serum nach Blutentnahme sind 2 Fraktionen durch Immundiffusion mit Anti- $\beta_{1}-\mathrm{C} / \mathrm{A}-\mathrm{Globulinserum} \mathrm{nach-}$ zuweisen und im Disk-Pherogramm den beiden eng zusammenliegenden Banden kathodisch vom Transferrin zuzuordnen (s. Abb. 6). Nach 20 Tagen findet sich in demselben Serum neben den beiden identifizierten Fraktionen eine dritte, schneller wandernde Fraktion, die ebenfalls mit Anti- $\beta_{1}-\mathrm{C} / \mathrm{A}-$ Globulinserum präzipitiert (s. Abb. 7). Auf die Beobachtung des genauen zeitlichen Verlaufs der Transformation des $\beta_{1}$-C-Globulins wurde im Rahmen dieser Arbeit verzichtet.
Die einzelnen Haptoglobin-Fraktionen lassen sich mit unserer Technik immunologisch darstellen und den angefärbten Banden des Disk-Pherogramms zuordnen. Die 4-5 Fraktionen des Hp 2-2 zwischen $\beta$-Lipoprotein und $\alpha_{2}$-Makroglobulin (s. Abb. 9) sind jedoch so fein, daß sie nur im Trenngel und nicht auf photographischen Abbildungen zu erkennen sind. Dabei wird deutlich, daß sowohl in den beiden $\alpha_{2}$-Makroglobulinbanden als auch in der kathodisch gelegenen Fraktion des $\beta_{1}-\mathrm{C} / \mathrm{A}-$ Globulins Haptoglobulinkomponenten $\mathrm{zu}$ finden sind.

In der Disk-Elektrophorese wurden die zwei eng zusammenliegenden und deutlich erkennbaren Banden im kathodischen Drittel des Gels schon in früheren Untersuchungen als $\alpha_{2}$-Makroglobulin nominiert und konnten mit der Immundiffusion von uns bestätigt werden. $\mathrm{Zu}$ bemerken ist, daß sowohl in ganz frisch entnommenem Blut als auch in gealtertem Serum zwei Fraktionen vorliegen. Eine Variation wurde von uns lediglich in der Intensität der Färbung der beiden Banden gefunden. Bei Verwendung von 5\% Trenngel wandert in der DiskElektrophorese das $\beta$-Lipoprotein $1-2 \mathrm{~mm}$ in das

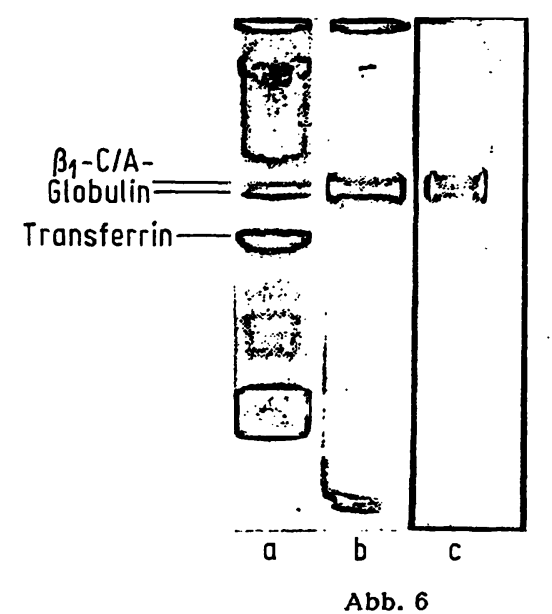

Identifizierung von $\beta_{1}-\mathrm{C} / \mathrm{A}-\mathrm{Globulin}$ ( $30 \mathrm{Min}$. altes Serum). $\mathrm{a}=$ DiskElektrophorese von Humanserum. $b=$ Angefärbtes Immunpräzipitat

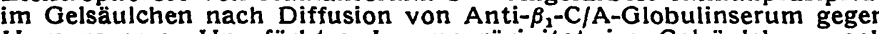
Humanserum. Ungefärbtes Immunpräzipitat im Gelsäulchen nach

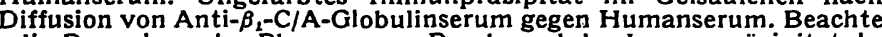
die Doppelung der Pherogramm-Bande und der Immunpräzipitate!

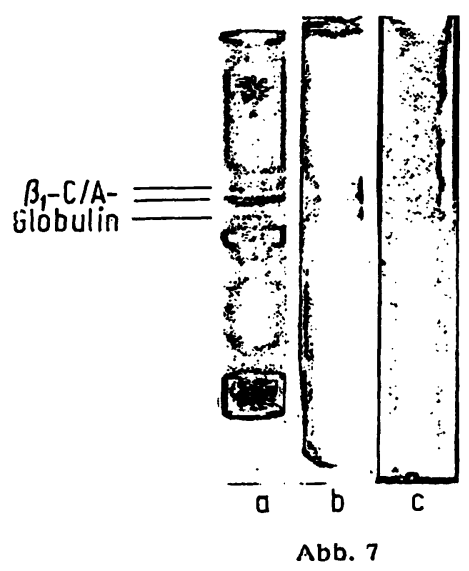

Identifizierung von $\beta_{1}-\mathrm{C} / \mathrm{A}-$ Globulin (20 Tage altes Serum). a $=$ DiskElektrophorese von Humanseruın. Angefärbles Immunpräzipitat im

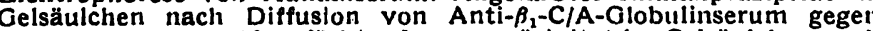
Humanseruın. $c$ - Ungefärbtes Immunpräzipitat im Gelsäulchen nach

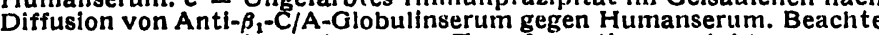
das neu hinzugekommene Transformationsprodukt 
Trenngel ein. Das Immunpräzipitat im Gel ergibt ebenfalls eine scharf begrenzte Fraktion.

Die von uns durchgeführte Identifizierung der Immunglobuline nach disk-elektrophoretischer Trennung zeichnet sich vor allem durch die überraschend schlechte Anfärbbarkeit des $I g G$-Präzipitats aus. Eine klare $\mathrm{Zu}-$ ordnung zum Disk-Elektropherogramm ist uns nicht gelungen. Es wird lediglich deutlich, daß die Hauptmenge als diffuse Zone im Haptoglobinbereich liegt, und $\mathrm{da} ß$ sie von dort sowohl kathodisch als auch anodisch in unscharfer Begrenzung ausläuft. Auffallend ist der geringe IgG-Anteil im Bereich zwischen $\alpha_{2}$-Makroglobulin und $\beta$-Lipoprotein. Besser läßt sich das $\operatorname{Ig} A$ darstellen und im Disk-Pherogramm erstmalig klar lokalisieren. Es repräsentiert wie das IgG keine selbständige Bande, sondern bildet eine Zone aus, die jedoch schmaler und mit den Präzipitationsbögen deutlicher als die des IgG abgrenzbar ist. Aus dem Vergleich mit dem $\operatorname{IgG}$ ergibt sich weiterhin, daß es ungefähr mit dem anodischen Abschnitt des IgG"zusammenfällt (s. Abb. 8). Das IgM-Immunglobulin tritt nicht in das Trenngel ein.

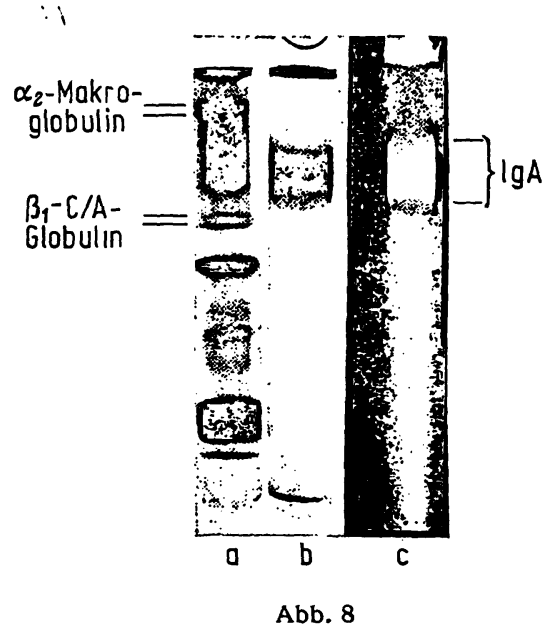

Identifizierung von IgA. $a=$ Disk-Elektrophorese von Humanserum. $\mathrm{b}=$ Angefärbtes Immunpräzipitat im Gelsäulchen nach Diffusion von Anti-IgA-Serum gegen Humanserum. $c=$ Ungefärbtes Immunpräzipitat im Gelsäulchen nach Diffusion von Anti-IgA-Serum gegen Humanserum

In der Disk-Elektrophorese ist die Albuminbande im vorderen Drittel des Gelsäulchens von allen Fraktionen am intensivsten mit Amidoschwarz angefärbt und bedarf an sich keiner weiteren Identifizierung. Überraschenderweise stellt sich jedoch das Albuminpräzipitat sehr schwer dar, und nur durch die Variation der Antigen-Antikörper-Relation (0,02 $\mathrm{m} l \quad 1: 10$ verdünntes Serum statt 0,4 und $0,5 \mathrm{~m} l$ unverdünntes Antiserum statt $1 \mathrm{ml}$ Antiserum $+1 \mathrm{~m} l$ physiol. $\mathrm{NaCl}-$ Lösung) läßt sich ein nicht einmal vollständiges Immunpräzipitat sichtbar machen. In einem Trennlauf fanden sich nach Diffusion von Anti-Albuminserum drei weitere Präzipitationen im Postalbuminbereich. Eine $\mathrm{Zu}-$ ordnung zum Disk-Elektropherogramm war jedoch nicht eindeutig möglich.

Abschließend sind alle von uns identifizierten Proteinfraktionen schematisch dargestellt (s. Abb. 9).

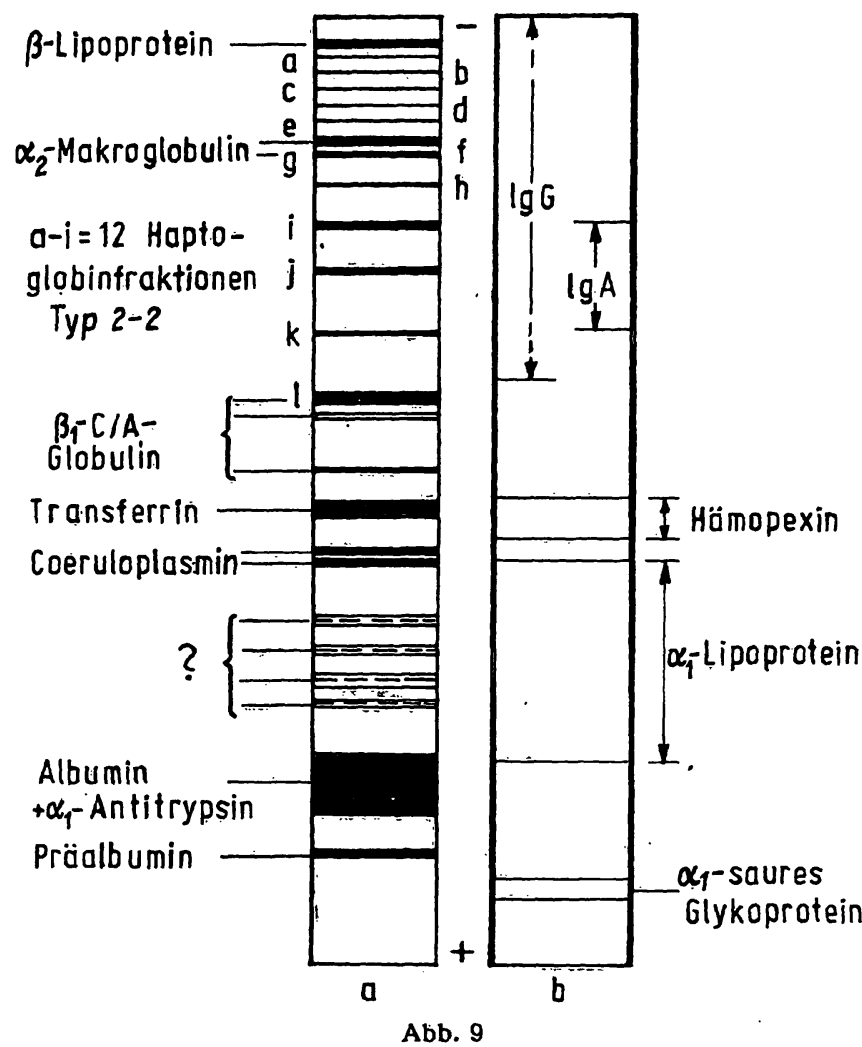

Schematische Darstellung der hier immunologisch identifizierten Serumproteine nach disk-elektrophoretischer Trennung. $a=$ Lokalisierung der diskreten Banden: $\beta$-Lipoprotein, $\alpha_{2}$-Makroglobulin, die etwa 12 Haptoglobinfraktionen des Typs 2-2, $\beta_{1}-$ C/A-Globulin, Transferrin, Coeruloplasmin, Albumin, $\alpha_{1}$-Antitrypsin, Präalbumin. Die $\mathrm{f}-$, g- und l-Fraktion des Hp 2-2 fallen in diesem Serum mit $\alpha_{2}$-Makroglobulin bzw. $\beta_{1}-$ C/A-Globulin zusammen. Die mit einem Fragezeichen versehenen vier Fraktionen im Postalbuminbereich konnten wir nicht eindeutig identifizieren. $b=$ Dàrstellung der Serumproteine, die keine anfärbbaren diskreten Banden, sondern Żonen ausbilden, die erst durch spezifische Immunpräzipitationen sichtbar werden; IgG, IgA, Hämopexin, $\alpha_{2}$-Lipoprotein, $\alpha_{2}$-saure Glykoprotein

\section{Diskussion}

$\mathrm{Da}$ die optimale Trennleistung der Disk-Elektrophorese für klinische Fragestellungen nur bei eindeutiger Identifizierung der erhaltenen Proteinbariden eingesetzt werden kann, wurde mit einer hier entwickelten Immunpräzipitationstechnik in den Polyacrylamidgel-Zylindern eine Identifizierung der Eiweißfraktionen mit monovalenten Antiseren durchgeführt. Mit dieser Technik erhoben wir in einer für Immunpräzipitationsnachweise relativ kurzen Zeit von 2-24 Stdn. gut reproduzierbare Befunde. Die Rotation der Gelzylinder im Antiserumgemisch rationalisiert den Antiserumverbrauch und garantiert gleichmäßige Diffusionsbedingungen. Gegenüber den Arbeiten von BIEL und Zwrster, BEDNARIK u. a. (4-9) konnte auf eine Diffusion der polyacrylamidgel-getrennten Eiweißfraktionen in Agargel verzichtet werden. Hierdurch wurden die technische Durchführung einfacher, die Fehlerquelle reduziert und die Versuchsdauer erheblich verkürzt. Die ungefärbten monovalenten Immunpräzipitate ermöglichen nach spätestens 3 Stdn. eine Identifizierung der Serumproteine im Trenngel. Die definitive Dokumentierung wird durch die Amidoschwarz-Färbung der Immunpräzipitate erreicht und gelingt nach elektrophoretischer Auswaschung der Trenngele von nicht präzipitierten Proteinen. 
Durch eine für die Polyacrylamidgel-Entfärbung beschriebene Apparatur nach MAURER (10) ist zu erwarten, $\mathrm{da} ß$ sich die jetzige Auswaschzeit von $30 \mathrm{Stdn}$. erheblich verkürzt, da in diesem Gerät das gesamte elektrische Feld nur über die Gele von Pol zu Pol aufgebaut und damit der elektrophoretische Auswaschzeit potenziert werden.

Neben den methodischen Vorteilen zeigen die Befunde, $\mathrm{da} ß$ die hier angewandte Technik für die in der Identifizierung auch schwer lokalisierbarer Serumproteinfraktionen besonders gut geeignet ist.

Im Präalbuminbereich finden BIEL und Zwisler (4, 5) mit der OssermanN-Technik sowie Schmidt (11) durch Vergleichsuntersuchungen gereinigter Serumkomponenten, da $\beta$ das $\alpha_{1}$-saure Glykoprotein zwischen Albumin und Präalbumin lokalisiert ist, während GEYER und Mitarbeiter (12) das $\alpha_{1}$-saure Glykoprotein der Präalbuminbande zuordnen und das immunologisch definierte Präalbumin in die Albuminbande verlegen. Wir fanden $\mathrm{da} \beta$ sich das $\alpha_{1}$-saure Glykoprotein als kohlenhydratreichstes Protein des Serums nicht mit wäßr., essigsaurem Amidoschwarz anfärbt. Als Erklärung hierfür kann die Tatsache angeführt werden, daß Glykoproteine dieses hohen Kohlenhydratgehaltes in 7 proz. Essigsäure nicht fällbar sind und somit vor allem bei elektrophoretischer Entfärbung der Gele aus denselben herauswandern. Im immunologischen Nachweis ist das $\alpha_{1}$-saure Glykoprotein eindeutig als schnellste Fraktion der Disk-Trennung anzusprechen (s. Abb. 2 u. 3).

Nach manchen Trennungen fiel in unseren Versuchen das Präalbumin mit der Albuminbande zusammen. Wird jedoch eine Präalbuminbande im Disk-Elektropherogramm färberisch dargestellt, entspricht ihre Lokalisation immer dem monovalenten Anti-Präalbuminpräzipitat (s. Abb. 1).

Im Albuminbereich ist neben der Hauptfraktion Albumin, $\alpha_{1}$-Antitrypsin, ein Teil des $\alpha_{1}$-Lipoproteins und u. U. Präalbumin lokalisiert. Die Amidoschwarz-Intensität des "Albumin" kann durch diese Komponenten potenziert werden.

Im Postalbuminbereich konnte die von CLARKe (13) und BIEL und ZwTSLER (4) beschriebene Lokalisation des Coeruloplasmins bestätigt werden. Wir fanden jedoch $z$ wei Banden, die dem von Morell und SCHEINBERg (14) mit der Stärkegel-Elektrophorese erhobenen Befund entsprechen könnten. Die Autoren nehmen eine Heterogenität des Coeruloplasmins an. Bei der Antigenidentität ist ein unterschiedlicher Aggregationszustand der beiden Coeruloplasminfraktionen am .wahrscheinlichsten. Die übrigen Proteinbanden des Postalbuminbereichs konnten wir mit den zur Verfügung stehenden monovalenten Antiseren nicht identifizieren. PASTEwka und Mitarbeiter (15) und PeACOCK und Mitarbeiter (16) sowie BIEL und Zwisler (4) nehmen an, daß hier die GcGlobuline und das $\alpha_{2}$-HS-Globulin lokalisiert seien. $\mathrm{Da}_{\mathrm{a}}$ das handelsübliche Anti-Gc-Globulinserum jedoch zusätzlich Anti- $\alpha_{1}$-Lipoprotein enthält, das über den gesamten Postalbuminbereich diffus wandert (s. Abb. 4), kann mit unserer Technik eine sichere immunologische
Identifizierung der Gc-Globuline nicht durchgeführt werden. Anti- $\alpha_{2}-H S-G l o b u l i n s e r u m$ stand uns nicht zur Verfügung. Weiterhin sind in diesem Bereich die von GEYER und Mitarbeitern (12) diskutierten Albuminaggregationen zu berücksichtigen.

In dem nachfolgenden kathodischen Abschnitt der Gelzylinder läßt sich Hämopexin nur immunologisch zwischen Transferrin und Coeruloplasmin nachweisen (s. Abb. 5). Die Präzipitationslinie des Transferrin entspricht der aus dem Disk-Elektropherogramm bekannten Lokalisation.

Durch die Immunpräzipitation mit monovalentem $\beta_{1}$ C/A-Globulinserum konnten wir erstmalig zeigen, da $\beta$ bereits 30 Min. nach Entnahme des Serums zwei immunologisch identische Fraktionen vorliegen (s. Abb. 6). $\mathrm{Da}$ sich nach 20 tägiger Lagerung desselben Serums eine dritte Fraktion mit Anti- $\beta_{1}-\mathrm{C} / \mathrm{A}$-Globulinscrum nachweisen läßt (s. Abb. 7), möchten wir diese Fraktion als das von MüLlER-Eberhard und Mitarbeitern (17) beschriebene Transformationsprodukt $\beta_{1}$-A-Globulin ansprechen. Die in frischem Serum beobachtete Doppelbande würde demnach zwei Aggregationszuständen des $\beta_{1}$-C-Globulins entsprechen.

Leider hat sich die Hoffnung nicht erfüllt, den $\gamma$-Globulinbereich des Disk-Gels mit der Präzipitationstechnik weiter zu differenzieren, um neue Informationen über die Immunglobuline zu erhalten. Wir können jedoch mit dieser Methode relativ genau die Lage des IgA festlegen (s. Abb. 8). Letztlich bestimmen drei große Proteinfraktionen das Bandenbild des $\gamma$-Globulinbereichs: Haptoglobin, $\alpha_{2}$-Makroglobulin und $\beta$-Lipoprotein (s. Abb. 9). Durch die Unbeweglichkeit des $\beta$-Lipoproteins können wir die unmittelbare Startzone nicht untersuchen. Die Identifizierung des $\beta$-Lipoproteins zeigt jedoch, daß diese Fraktion vollständig in das 5 proz. Trenngel einwandert, während das IgM am Startpunkt liegenbleibt.

Die Immundiffusion von polyvalenten Antiseren in das Trenngel führte schon BEDNARIK (7) in der horizontalen, kontinuierlichen Polyacrylamidgel-Elektrophorese durch, ohne überzeugende Ergebnisse zu erzielen. Auch in unserem Fall bilden sich nicht mehr als 10 Präzipitationsbanden aus. Durch die teilweise Überlagerung mehrerer Fraktionen im Trenngel ist eine bessere Auflösung nicht $\mathrm{zu}$ erwarten. Bei Verwendung von polyvalentem Antiserum ist deshalb die von BreL und Zwisler $(4,5)$ verwandte Technik zu empfehlen, da die Fraktionen durch die Diffusion in Agargel eine zusätzliche Trennung erfahren.

Die Úberlagerung einzelner Proteinfraktionen führt im Disk-Elektropherogramm zu Interpretationsschwierigkeiten und schließt exakte quantitative Aussagen durch Densitometrie $(11,18)$ aus. So ist beispeilsweise die scharf begrenzte Amidoschwarzbande im Albuminbereich eine Summation von Albumin, $\alpha_{1}$-Antitrypsin, $\alpha_{1}$-Lipoprotein und u. U. auch von Präalbumin. Eine Änderung der Bandenintensität ist folglich nicht in jedem Fall mit einer Albuminvermehrung oder -verminderung identisch. Summationen verschiedener Pro- 
teinfraktionen liegen, wie die Ergebnisse zeigen (s. Abb. 9), auch im Postalbuminbereich, in der Hämopexin-Zone und im gesamten $\gamma$-Globuilinbereich vor. Weiterhin zeigen mehrere Arbeiten $(15,16,18,19)$, daß in Normalseren Anzahl und Intensität der Banden sehr variabel sind. Durch die Vielzahl dieser eng beieinanderliegenden Banden können nur markante Veränderungen oder Vermehrungen im Disk-Elektropherogramm re- gistriert werden $(11,13,20-22)$, verbindliche diagnostische Aussagen sind jedoch nur nach immunologischer Identifizierung dieser Fraktionen möglich. Hierfür erscheint uns die hier entwickelte Methode geeignet, da sie die Interpretation der Banden schnell und sicher erlaubt. Als besonders wertvoll erweist sie sich für die Fälle, in denen färberisch nicht erfaßbare Proteinfraktionen nachzuweisen sind.

\section{Literatur}

1. Ornstein, L., Annals N. Y. Acad. Sc. 121, 321 (1964). - 2. Davis, B. J., Annals N. Y. Acad. Sc. 121, 404 (1964). - 3. Maurer, H. R., Disk-Elektrophorese, Theorie und Praxis der diskontinuierlichen Polyacrylamidgel-Elektrophorese, Walter de Gruyter \& Co., Berlin (1968). - 4. BIEL, H. und O. ZwIsLER, BehringwerkMitt., 46, 141 (1966). - 5. Zwisler, O. und H. Brex, BehringwerkMitt., 46, 129 (1966). - 6. Bednarik, T., Clin. chim. Acta (Amsterdam) 17, 132 (1967). - 7. Bednarik, T., Clin. chim. Acta (Amsterdam) 15, 172 (1967). - 8. Darcy, D. A., Clin. chim. Acta (Amsterdam) 21,161 (1968). - 9. Afonso, E., Clin. chim. Acta (Amsterdam) 10, 114 (1964). - 10. MAURER, H. R., diese Z. 4, 85 (1966). 11. Schмid, U., Med. Dissertation, Univ.-Heidelberg (1969). 12. Geyer, E., S. Marghescu und J. J. Mülleer, Klin. Wschr. 45, 717 (1967). - 13. Clarke, J. T., Annals N. Y. Acad. Sc. 121,
428 (1964). - 14. Morell, A. G. und I. M. Scheinberg, Science, Washington 131, 930 (1960). - 15. Pastewka, J. V., A. T. Ness und A. C. PeAcock, Clin. chim. Acta (Amsterdam) 14, 219 (1966). 16. Peacock, A. C., S. L. Bunting und K. G. QueEn, Science, Washington 147, 1451 (1965). - 17. Müller-Eberhard, H. J., U. Nirsson und T. Aronsson, J. Exper. Med., 111, 201 (1960). 18. Delank, H. W., Klin. Wschr. 46,779 (1968). - 19. FellgenhaUER, K. S., S. BaCh und A. Stammler, Klin. Wschr. 45, 371 (1967). - 20. Isicher, U. P., Med. Dissertation, Univ. München (1966). - 21. Zingale, S. B., C. A. Mattrolt, H. D. Bohner und M. P. Bueno, Blood, 22, 152 (1963). - 22. Price, W. H., H. Harrison und S. H. Ferebee, Annals N. Y. Acad. Sc. 121, 460 (1964).
Prof. Dr. H. Weicker 6900 Heidelberg Hospitalstr. 3 